\title{
Translation of the updated clinical frailty scale 2.0 into Danish and implications for cross-sectoral reliability
}

\author{
Anders Fournaise ${ }^{1,2,3^{*}+}$ (D), Søren Kabell Nissen ${ }^{4,5+}$ (D) Jørgen T. Lauridsen ${ }^{6}$ (D) Jesper Ryg ${ }^{2,7}$ (D), Christian H. Nickel ${ }^{4,8}(\mathbb{D}$, \\ Claire Gudex ${ }^{7,9}$ (D) Mikkel Brabrand ${ }^{4,5,7,10}$ (D) Lone Musaeus Poulsen ${ }^{11,12}$ (D) and Karen Andersen-Ranberg ${ }^{2,3,7}$ (D)
}

\begin{abstract}
The Clinical Frailty Scale, which provides a common language about frailty, was recently updated to version 2.0 to cater for its increased use in areas of medicine usually involved in the care and treatment of older patients. We have previously translated the Clinical Frailty Scale 1.2 into Danish and found inter-rater-reliability to be excellent for primary care physicians, community nurses, and hospital doctors often involved in cross-sectoral collaborations. In this correspondence we present the Danish translation and cultural adaption of the Clinical Frailty Scale 2.0. Our recent findings on cross-sectoral inter-rater reliability for the Clinical Frailty Scale 1.2 are likely also applicable for the Clinical Frailty Scale 2.0.
\end{abstract}

Keywords: Cross-sectoral collaboration, Continuity of care, ISPOR translation, Validation, Reliability, Geriatrics, Clinical frailty scale

\section{Background}

The previous version of the Clinical Frailty Scale (CFS 1.2) was recently translated into Danish and published alongside results from a cross-sectoral inter-rater reliability study among primary care physicians, community nurses, and hospital doctors [1]. We found excellent inter-rater reliability across these four groups of health care professionals, supporting the notion that the CFS has the potential to serve as a common reference tool when treating and rehabilitating older patients. Since then, the developers of the CFS have modified the instrument (CFS 2.0) to facilitate its use as a triage tool regarding intensive care treatment for older patients with COVID-19 $[2,3]$ and to increase its relevance in areas of

\footnotetext{
* Correspondence: anders.fournaise@rsyd.dk

${ }^{\dagger}$ Anders Fournaise and Søren Kabell Nissen contributed equally to this work.

'Department of Cross-sectoral Collaboration, Region of Southern Denmark, 7100 Vejle, Denmark

2Department of Geriatric Medicine, Odense University Hospital, 5000 Odense, Denmark

Full list of author information is available at the end of the article
}

medicine not usually involved in the assessment of frailty $[4,5]$. Here, we present a translation of the CFS 2.0, briefly summarize changes between the two versions, and discuss possible implications for the cross-sectoral reliability.

\section{Results}

As with the CFS 1.2, we translated the CFS 2.0 in accordance with the ISPOR guidelines [6]. This process is designed to ensure cultural and conceptual compliance with the source instrument $[7,8]$. The CFS 2.0 and its Danish translation (CFS-DK 2.0) are presented in Fig. 1, and the Danish translation report is available in the 'Additional file 1'. In 'Additional file 2', the differences between CFS 1.2 and CFS 2.0 are highlighted in the English and Danish versions.

\section{Discussion}

The CFS is validated for assessing the habitual health state of patients rather than the state of acute illness [7], 


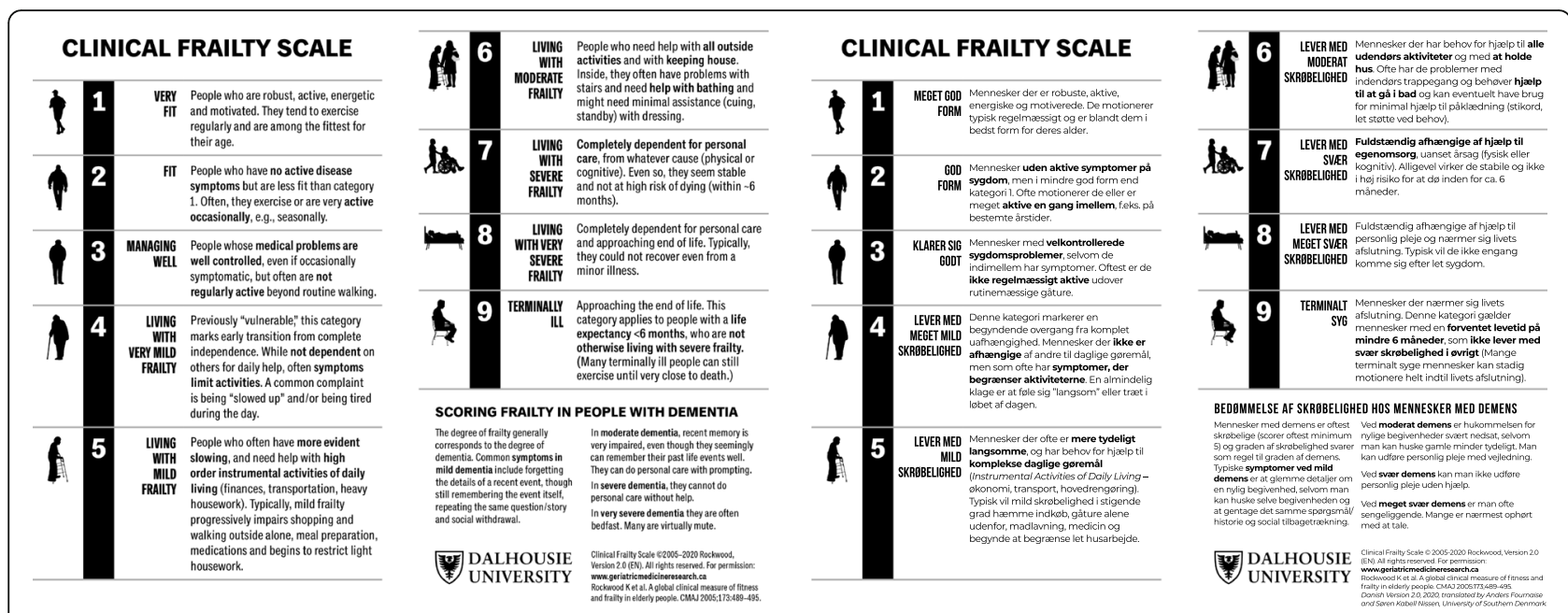

Fig. 1 Legend: The Clinical Frailty Scale 2.0 source instrument in English (left) and the Danish translation (right). Printed with permission from copyright holder

a caveat not immediately evident from the 9-level pictogram scale. To remedy this, the developers have revised the level headings in CFS 2.0 to indicate that the health care professional should consider the patient's baseline health state (for example, "vulnerable" has become "living with very mild frailty") [3]. However, health care professionals will still be faced with a challenge to determine when the health state of the patient changed from habitual to acutely ill. This tipping point varies from patient to patient, and for the CFS 2.0 it remains relevant for clinicians to include information from relatives and from other health care professionals in crosssectoral collaborations.

Other changes include additional information on differentiating between severe and very severe dementia (for health care professionals who are less familiar with the spectrum of dementia diseases) and the writing out of "instrumental activities of daily life", which was previously presented just in its abbreviated form, "IADL"). From our experiences of translating both the CFS 1.2 and 2.0, we agree with instrument developers that the CFS 2.0 is likely to be more relevant than CFS 1.2 for assessing acutely ill older patients and patients living with severe dementia [3].

In our inter-rater reliability study on CFS-DK 1.2 we found little variance among raters when rating CFS levels 4 and 5, the threshold at which the term "frail" is included in headings [1]. However, a recent study on older ( $\geq 80$ years of age) patients in intensive care units found high variance among raters when differentiating these two levels using the CFS version 1.2 [9]. Though the study also confirms a high ICC for the CFS 1.2 in the intensive care setting, differentiating CFS level 4 and 5 may pose a challenge in the CFS 2.0 despite the change of heading in
CFS level 4 from "vulnerable" to "living with very mild frailty" [3].

We consider the differences between CFS 1.2 and 2.0 versions to be minor and that the results of our recent inter-rater reliability study on CFS-DK 1.2 are likely still applicable to the 2.0 version [1]. The inter-rater reliability study used clinical vignettes to describe individuals in their habitual state, and raters were introduced to the CFS 1.2 (including an explanation of the abbreviation IADL and the importance of scoring the subject according to habitual health state) before they rated the vignettes. Furthermore, none of the vignettes described severely or very severely demented patients (which the CFS 2.0 now distinguishes).

\section{Conclusion}

A Danish translation of the updated Clinical Frailty Scale 2.0 is now available, and we refer potential users to our recent cross-sectoral inter-rater reliability study performed with the CFS 1.2. We believe the results of this study will still be relevant for the CFS-DK 2.0 in view of the minor differences between the versions.

\section{Abbreviations}

CFS: Clinical Frailty Scale; IADL: Instrumental Activities of Daily Life; ICC: Intraclass Correlation Coefficient

\section{Supplementary Information}

The online version contains supplementary material available at https://doi. org/10.1186/s12877-021-02222-w.

Additional file 1. Final report - ISPOR translation of Clinical Frailty Scale 2.0 into the Danish language.

Additional file 2. Clinical Frailty Scale version 1.2 and 2.0 in English and Danish, with the differences between the 1.2 and 2.0 versions highlighted. 


\section{Acknowledgements}

The authors acknowledge copyright holder and developer of the source CFS, Kenneth Rockwood, for allowing translation and validation of the CFS 2.0. For forward translation, the authors acknowledge Jessica Joan Williams. For participating in the cognitive debriefing and validation of the CFS-DK 2.0, the authors acknowledge Jens Vestergaard, Christel Kronborg, Katja Thomsen, Lars Matzen, Susan Feldborg, Lone Lauritsen, Nina Andersen-Ranberg, and Ulf Pedersen. For proofreading, the authors acknowledge Christina Boesen Kristensen. Finally, the authors also acknowledge David Hass from the Open Patient data Explorative Network (OPEN), Odense University Hospital, Region of Southern Denmark for assistance in data management.

\section{Authors' contributions}

AF and SKN conceived this study and contributed equally to all aspects of this manuscript. AF and SKN performed the collection of data. AF, SKN, CG, $J R, M B, C H N$, JTL, LMP, and KAR contributed to the design, data interpretation, and writing of the manuscript. All authors have commented, read, and approved the final manuscript, and agree to be personally accountable for the accuracy or integrity of any part of the manuscript

\section{Funding}

This correspondence was supported by funding from the University of Southern Denmark (SKN), Region of Southern Denmark (SKN, AF), and Innovation Fund Denmark (AF). The funding bodies had no influence on design, data collection, interpretation, or decision on publication.

\section{Availability of data and materials}

The datasets used and/or analysed during the current study are available from the corresponding author on reasonable request.

\section{Declarations}

\section{Ethics approval and consent to participate}

In accordance with the guidelines from the Danish National Ethics Committee, the study was not subject to notification [10]. Written informed consent was obtained from all health care professionals performing the cognitive debriefing of the CFS-DK 2.0. The study was approved by the Danish Data Protection Agency (rec. nr. 20/16898).

\section{Consent for publication}

Not applicable.

\section{Competing interests}

The authors declare that they have no competing interests.

\section{Author details}

'Department of Cross-sectoral Collaboration, Region of Southern Denmark, 7100 Vejle, Denmark. ${ }^{2}$ Department of Geriatric Medicine, Odense University Hospital, 5000 Odense, Denmark. ${ }^{3}$ Epidemiology, Biostatistics and Biodemography, Department of Public Health, University of Southern Denmark, 5000 Odense, Denmark. ${ }^{4}$ Institute of Regional Health Research, Centre South West Jutland, University of Southern Denmark, 6700 Esbjerg, Denmark. ${ }^{5}$ Department of Emergency Medicine, Hospital of South West Jutland, 6700 Esbjerg, Denmark. ${ }^{6}$ Department of Business and Economics, University of Southern Denmark, 5230 Odense, Denmark. ${ }^{7}$ Department of Clinical Research, University of Southern Denmark, 5000 Odense, Denmark. ${ }^{8}$ Emergency Department, University Hospital Basel, University of Basel, 4031 Basel, Switzerland. ${ }^{9}$ Open Patient data Explorative Network (OPEN), Region of Southern Denmark, 5000 Odense, Denmark. ${ }^{10}$ Department of Emergency Medicine, Odense University Hospital, 5000 Odense, Denmark. ${ }^{11}$ Department of Anaesthesiology, Zealand University Hospital, 4600 Køge, Denmark.

${ }^{12}$ Collaboration for Research in Intensive Care (CRIC), 2100 Copenhagen, Denmark.

\section{Received: 31 March 2021 Accepted: 15 April 2021}

Published online: 21 April 2021

\section{References}

1. Nissen SK, Fournaise A, Lauridsen JT, Ryg J, Nickel CH, Gudex C, et al. Crosssectoral inter-rater reliability of the clinical frailty scale - a Danish translation and validation study. BMC Geriatr. 2020;20(1):443. https://doi.org/10.1186/ s12877-020-01850-y.

2. National Institute for Health and Care Excellence. Assess frailty COVID-19 rapid guideline : critical care in adults ( Last update : 03 September 2020 ). 2020. https://www.nice.org.uk/guidance/ng159. Accessed 20 Nov 2020.

3. Rockwood $\mathrm{K}$, Theou $\mathrm{O}$. Using the clinical frailty scale in allocating scarce health care resources. Can Geriatr J. 2020;23(3):210-5. https://doi.org/10. 5770/cgj.23.463.

4. Theou O, Squires E, Mallery K, Lee JS, Fay S, Goldstein J, et al. What do we know about frailty in the acute care setting? A scoping review. BMC Geriatr. 2018;18(1):139. https://doi.org/10.1186/s12877-018-0823-2.

5. Church S, Rogers E, Rockwood K, Theou O. A scoping review of the clinical frailty scale. BMC Geriatr. 2020;20(1):393. https://doi.org/10.1186/s12877-02001801-7.

6. Wild D, Grove A, Martin M, Eremenco S, McElroy S, Verjee-Lorenz A, et al. Principles of good practice for the translation and cultural adaptation process for patient-reported outcomes (PRO) measures: report of the ISPOR task force for translation and cultural adaptation. Value Heal. 2005;8(2):94104. https://doi.org/10.1111/j.1524-4733.2005.04054.x.

7. Rockwood K, Song X, MacKnight C, Bergman H, Hogan DB, McDowell I, et al. A global clinical measure of fitness and frailty in elderly people. CMAJ. 2005;173(5):489-95. https://doi.org/10.1503/cmaj.050051.

8. Dalhousie University. Clinical Frailty Scale. 2020; https://www.dal.ca/sites/ gmr/our-tools/clinical-frailty-scale.html. Accessed 15 May 2020.

9. Flaatten H, Guidet B, Andersen FH, Artigas A, Cecconi M, Boumendil A, et al. Reliability of the clinical frailty scale in very elderly ICU patients: a prospective European study. Ann Intensive Care. 2021;11(1):22. https://doi. org/10.1186/s13613-021-00815-7.

10. National Committee on Health Research Ethics. What to notify? 2020. https://en.nvk.dk/how-to-notify/what-to-notify. Accessed 20 May 2020.

\section{Publisher's Note}

Springer Nature remains neutral with regard to jurisdictional claims in published maps and institutional affiliations.
Ready to submit your research? Choose BMC and benefit from:

- fast, convenient online submission

- thorough peer review by experienced researchers in your field

- rapid publication on acceptance

- support for research data, including large and complex data types

- gold Open Access which fosters wider collaboration and increased citations

- maximum visibility for your research: over $100 \mathrm{M}$ website views per year

At $B M C$, research is always in progress.

Learn more biomedcentral.com/submissions 